\title{
Clinical Study \\ Xenon Anesthesia Improves Respiratory Gas Exchanges in Morbidly Obese Patients
}

\author{
Antonio Abramo, ${ }^{1}$ Claudio Di Salvo, ${ }^{1}$ Francesca Foltran, ${ }^{1}$ Francesco Forfori, ${ }^{1}$ \\ Marco Anselmino, ${ }^{2}$ and Francesco Giunta ${ }^{1}$ \\ ${ }^{1}$ Anestesia e Rianimazione Universitaria IV, Azienda Ospedaliera Universitaria Pisana, Via Roma 67, Pisa 56100, Italy \\ ${ }^{2}$ Bariatric Surgery Unit, Azienda Ospedaliera Universitaria Pisana, Via Roma 67, Pisa 56100, Italy \\ Correspondence should be addressed to Antonio Abramo, dino987@libero.it
}

Received 31 July 2009; Revised 13 November 2009; Accepted 11 January 2010

Academic Editor: Francesco Papadia

Copyright (C) 2010 Antonio Abramo et al. This is an open access article distributed under the Creative Commons Attribution License, which permits unrestricted use, distribution, and reproduction in any medium, provided the original work is properly cited.

\begin{abstract}
Background. Xenon-in-oxygen is a high density gas mixture and may improve $\mathrm{PaO} 2 / \mathrm{FiO} 2$ ratio in morbidly obese patients uniforming distribution of ventilation during anesthesia. Methods. We compared xenon versus sevoflurane anesthesia in twenty adult morbidly obese patients $(\mathrm{BMI}>35)$ candidate for roux-en-Y laparoscopic gastric bypass and assessed $\mathrm{PaO} 2 / \mathrm{FiO} 2$ ratio at baseline, at $15 \mathrm{~min}$ from induction of anaesthesia and every $60 \mathrm{~min}$ during surgery. Differences in intraoperative and postoperative data including heart rate, systolic and diastolic pressure, oxygen saturation, plateau pressure, eyes opening and extubation time, Aldrete score on arrival to the PACU were compared by the Mann-Whitney test and were considered as secondary aims. Moreover the occurrence of side effects and postoperative analgesic demand were assessed. Results. In xenon group PaO2-FiO2 ratio was significantly higher after $60 \mathrm{~min}$ and $120 \mathrm{~min}$ from induction of anesthesia; heart rate and overall remifentanil consumption were lower; the eyes opening time and the extubation time were shorter; morphine consumption at 72 hours was lower; postoperative nausea was more common. Conclusions. Xenon anesthesia improved $\mathrm{PaO} 2 / \mathrm{FiO} 2$ ratio and maintained its distinctive rapid recovery times and cardiovascular stability. A reduction of opioid consumption during and after surgery and an increased incidence of PONV were also observed in xenon group.
\end{abstract}

\section{Introduction}

Arterial oxygenation may decrease during anesthesia with mechanical ventilation $[1,2]$. This phenomenon is more evident in obese than in normal-weight patients [3, 4]. Increase in body mass index (BMI) is directly related to the impairment of arterial oxygenation, which is mainly attributable to development of ventilation-perfusion (V/Q) mismatches and intrapulmonary shunt (i.e., atelectasis); in fact this is more common during laparoscopy $[5,6]$. For these reasons in morbidly obese patients, various strategies have been proposed to improve gas exchange during general anesthesia $[7,8]$. Xenon is a N-Methyl-D-Aspartate (NMDA) receptor blocking agent which has become an alternative to the currently used inhaled anaesthetics $[9,10]$. The element xenon is a noble gas, has no harmful environmental effects, is associated with cardiovascular stability [9-11], and owns organoprotective properties, being able to interact with a variety of molecular targets. Several experimental studies have demonstrated a reduction in cerebral and myocardial infarction size after xenon inhalation and the up-regulation of several genes involved in cellular surviving pathways in several tissues [12-15]. Xenon has the lowest bloodgas coefficient (0.115) of all known anaesthetics making induction and recovery from anesthesia very fast [16]. Furthermore, "xenon in oxygen" is a high-density mixture that increases airway pressure and resistance by a rising the Reynold's number [17], but this reproducible effect does not assume certain clinic implications [18]. On the contrary, as elegantly described by Wood et al., breathing gas mixtures with increased density may cause a reduction of alveolararterial oxygen difference $(\mathrm{AaDO} 2)$ and improves respiratory performances and distribution of ventilation, minimizing V/Q variances [19]. Despite arterial oxygen partial pressure 
( $\mathrm{PaO} 2)$, hemoglobin oxygen saturation $(\mathrm{SaO} 2)$ and $\mathrm{AaDO} 2$ are clinical indices commonly used for assessing lung function, as described by Zetterström et al.; the ratio of $\mathrm{PaO} 2$ to the inspired oxygen fraction $(\mathrm{PaO} 2 / \mathrm{FiO} 2$ ratio) seems the most accurate and independent off all extrapulmonary variables $[20,21]$.

In this paper, we present for the first time intra and postoperative data on respiratory function, hemodynamic status, and recovery times from morbidly obese patients (BMI> 35) receiving xenon-remifentanil (XR) or sevoflurane-remifentanil (SR) anaesthesia. In particular, we tested the hypothesis that xenon anesthesia is able to improve $\mathrm{PaO} 2 / \mathrm{FiO} 2$ ratio. Furthermore, we tested the hypothesis that xenon, even in morbidly obese patients, maintains its pharmacologic properties characterized by cardiovascular stability and rapid recovery times. The incidence of side effects and the postoperative analgesic demand were also assessed.

\section{Methods}

The study was a prospective randomised partially blinded controlled trial. The protocol was approved by the local ethics committee, and all patients gave their informed consent before participation. A total of 20 adult morbidly obese patients scheduled for roux-en-Y laparoscopic gastric bypass were randomly recruited. Exclusion criteria were ASA IV, age $<18$ or $>60 \mathrm{yr}$, Mallampati IV. Monitoring included ECG, pulse oximetry, invasive arterial pressure, temperature, end-tidal carbon dioxide, oxygen and xenon concentrations. All intraoperative continuous variables were recorded every $3 \mathrm{~min}$. Arterial blood gas analysis was performed in the preoperative assessment, at $15 \mathrm{~min}$ after the induction of anaesthesia, and every $60 \mathrm{~min}$ during surgery. The A-line ARX index (AAI) was also monitored (AEP monitor, Alaris Medical Systerns, Inc, San Diego, CA) to provide information about depth of anaesthesia. Monitoring was performed to ensure AAI values $<30$, and data were recorded every $5 \mathrm{~min}$. After preoxygenation with O2 100\% for $5 \mathrm{~min}$, anaesthesia was induced in all patients with propofol $2 \mathrm{mg} / \mathrm{kg}$ i.v. dosed on real body weight (RBW) and remifentanil $0.5 \mathrm{mcg} / \mathrm{kg} / \mathrm{min}$ dosed on ideal body weight (IBW) according to Lorenz's formula (Ideal weight $=[$ height in $\mathrm{cm}-100$ ] - [height in $\mathrm{cm}-150] / 2$ ) by i.v. infusion over $60 \mathrm{sec}$. All patients were submitted to direct laringoscopy for intubation. Since mask ventilation was uncomplicated an i.v. bolus of cisatracurium $0.2 \mathrm{mg} / \mathrm{kg}$ IBW was given and intubation performed. All patients received remifentanil continuous infusion after intubation starting with $0.25 \mathrm{mcg} / \mathrm{kg} / \mathrm{min}$ IBW and cisatracurium $0.02 \mathrm{mg} / \mathrm{kg}$ IBW every $40 \mathrm{~min}$ titrated to clinical needs. No cisatracurium was given after the end of $2 \mathrm{nd}$ anastomosis ( 30 minutes before end of surgery). In both groups, a closed-circuit anaesthesia machine (Felix Dual, Taema, France) was used for gas delivery. Xe (LenoXe, Airliquide) administration started after accurate patient's denitrogenation ( $\mathrm{FiO} 2>97 \%, \mathrm{FeO} 2>92)$; midazolam $0.05 \mathrm{mg} / \mathrm{Kg}$ IBW was given in order to keep AAI $<30$ for the time, 7 to 10 minutes, occurring to reach $40 \%$ FeXe in closed circuit. Hypnosis was then maintained using
Xe 60-65\% in oxygen. In SR group, hypnosis was maintained with sevoflurane $1 \mathrm{MAC}$ in a mixture of oxygen-air. In both groups, ventilation was pressure-controlled (PCV), with FiO2 35\%, Peep 5, Vt $8-10 \mathrm{ml} / \mathrm{kg}$ IBW in order to maintain an end-expiratory carbon dioxide partial pressure (EtCO2) at $4.8-6.0 \mathrm{kPa}$. Haemodynamic parameters were maintained within $20 \%$ of preoperative values by adjusting remifentanil infusion accordingly. Normothermia $(35.5-37.0 \circ \mathrm{C})$ was achieved using warming blankets. AAI $<30$ was kept until the bandaging of the surgical fields were completed then anaesthesia was discontinued. The eyes opening time started with the closure of gas delivery and ended with eyes opening on command. When an adequate spontaneous ventilation, with an $\mathrm{EtCO} 2$ at 5.3-6.6 kPa, was maintained, the trachea was extubated and the patient was transferred into the post anesthesia care unit (PACU). A patient-controlled analgesia (PCA) device was then connected to a venous line delivering morphine on command.

2.1. Statistics and Sample Size Calculation. We decided to consider as clinically relevant a difference of 60 on $\mathrm{PaO} 2-$ $\mathrm{FiO} 2$ ratio among the groups, measured at 120 minutes after induction. Assuming a mean $\mathrm{PaO} 2-\mathrm{FiO} 2$ ratio (standard deviation) of 370 (55) in xenon group and 310 (35) in the other group, we estimated a sample size of 10 patients per group enough to detect a difference of 60 , at $5 \%$ level of significance with $80 \%$ power. We verified the existence of no significant differences in patient's demographic characteristics (age, sex, BMI), preoperative clinic characteristics, and duration of anaesthesia using the MannWhitney test for continuous variables and the Fisher's exact test for categorial variables. Differences in intraoperative and postoperative data including heart rate, systolic and diastolic pressure, oxygen saturation, plateau pressure, eyes opening and extubation time, and Aldrete score in the PACU were compared by the Mann-Whitney test and were considered as secondary aims. The existence of a significant difference on morphine consumption after 72 hours between the two groups was compared, and the occurrence of adverse events (hypertension, hypotension, bradycardia, PONV, postoperative headache, awareness) was finally evaluated. Statistical analysis was performed using Stata, version 9.2, on a Mac OS $\mathrm{X}$ operating system. Results were considered significant with a $P$ value $<.05$. All data are presented as median (range).

\section{Results}

The two groups were comparable as shown in Table 1 . No significant difference was recorded in anesthesia duration among the two groups, 150 (120-190) min in SR group and 152.5 (120-220) $\mathrm{min}$ in XR group; $P=.849$. Intraoperative data are shown in Table 2: there was no difference among the two groups in $\mathrm{PaO} 2-\mathrm{FiO} 2$ ratio at $15 \mathrm{~min}$ after the induction of anesthesia, but in XR group, $\mathrm{PaO} 2-\mathrm{FiO} 2$ ratio was significantly higher after 60 and $120 \mathrm{~min}$. Heart rate was significantly lower in XR group, while systolic pressure was significantly lower in SR group. No significant differences were recorded in diastolic pressure and oxygen saturation among the two groups; plateau pressure was significantly 
TABLE 1: Baseline data.

\begin{tabular}{lccr}
\hline & SR & XR & \\
\hline Age (yr) & $47.5(19-57)$ & $41(23-49)$ & .272 \\
BMI & $50.5(39-71)$ & $53(42-83)$ & .519 \\
Sex (males/females) & $6 / 4$ & $8 / 2$ & .628 \\
Heart rate (bpm) & $87.5(65-110)$ & $85.5(56-100)$ & .570 \\
Oxygen saturation (\%) & $95(91-100)$ & $95.5(89-98)$ & .623 \\
Systolic pressure (mmHg) & $160(120-168)$ & $137.5(115-175)$ & .178 \\
Diastolic pressure (mmHg) & $86(65-100)$ & $87.5(75-95)$ & .705 \\
PaO2-FiO2 ratio (on air) & $350(307-394)$ & $325.5(302-392)$ & .449 \\
\hline
\end{tabular}

Data are presented as median (range) for continuous variables; the number of males and females in each group is reported. $P<.05$ with Mann-Whitney test was considered significant.

TABLE 2: Intraoperative data.

\begin{tabular}{lccc}
\hline & SR & XR & $P$ \\
\hline $\mathrm{PaO} 2-\mathrm{FiO} 2$ ratio $15 \mathrm{~min}$ & $282(195-320)$ & $260(212-302)$ & .272 \\
$\mathrm{PaO} 2-\mathrm{FiO} 2$ ratio $60 \mathrm{~min}$ & $301.5(220-318)$ & $350.5(234-412)$ & .041 \\
$\mathrm{PaO} 2-\mathrm{FiO} 2$ ratio $120 \mathrm{~min}$ & $326.5(234-372)$ & $405.5(278-432)$ & .002 \\
$\mathrm{Heart}$ rate $(\mathrm{bpm})$ & $78(59-94)$ & $57.5(48-71)$ & .001 \\
Systolic pressure $(\mathrm{mmHg})$ & $106.5(94-124)$ & $121.5(110-148)$ & .008 \\
Diastolic pressure $(\mathrm{mmHg})$ & $67.5(58-83)$ & $69(62-78)$ & .545 \\
Oxygen saturation $(\%)$ & $96(93-97)$ & $95.5(94-97)$ & .477 \\
Plateau pressure $\left(\mathrm{mmH} \mathrm{m}_{2} \mathrm{O}\right)$ & $27(25-28)$ & $35(32-37)$ & .0001 \\
Remifentanil usage $(\mathrm{mcg})$ & $1597.5(1080-2425)$ & $762.5(415-1460)$ & .0001 \\
\hline
\end{tabular}

Data are presented as median (range). $P<.05$ with Mann-Whitney test was considered significant.

TABle 3: Postoperative data.

\begin{tabular}{lccr}
\hline & SR & XR & $P$ \\
\hline Eyes opening time (min) & $7.6(5.5-11.7)$ & $2.7(1.6-4.2)$ & .0002 \\
Extubation time (min) & $9.4(6.7-13.7)$ & $2.9(1.7-4.9)$ & .0002 \\
Aldrete score (PACU admission) & $9(8-10)$ & $9(8-10)$ & 1.000 \\
Morphine demand 72 hours (mg) & $26(13-41)$ & $9.5(0-16)$ & .0016 \\
\hline
\end{tabular}

Data are presented as median (range). $P<.05$ with Mann-Whitney test was considered significant.

TABLE 4: Occurrence of adverse events.

\begin{tabular}{lcccc}
\hline & $\begin{array}{c}\text { S. of patients } \\
\text { reporting adverse } \\
\text { events }\end{array}$ & $\begin{array}{c}\text { N. of adverse } \\
\text { events }\end{array}$ & $\begin{array}{c}\text { N. of patients } \\
\text { reporting adverse } \\
\text { events }\end{array}$ & $\begin{array}{c}\text { XR of adverse } \\
\text { events }\end{array}$ \\
\hline $\begin{array}{l}\text { Hypertension } \\
\text { Hypotension }\end{array}$ & 0 & 0 & 1 & 1 \\
Bradycardia & 2 & 2 & 0 & 0 \\
PONV & 1 & 2 & 2 & 6 \\
$\begin{array}{l}\text { Postoperative } \\
\text { headache }\end{array}$ & 1 & 1 & 4 & 2 \\
Awareness & 1 & 1 & 2 & 0 \\
\hline
\end{tabular}

Bradycardia was intended $a>20 \%$ deviation from mean baseline, hypertension $a>20 \%$ deviation from mean systolic baseline with stable heart rate and no other signs of low depth of anaesthesia and hypotension $a>20 \%$ deviation from mean systolic baseline. 
higher and overall remifentanil consumption significantly lower in XR group. Postoperative data are shown in Table 3: the eyes opening time and the extubation time were significantly shorter in XR group; morphine consumption after 72 hours was significantly lower in XR group. No difference among groups was noticed in Aldrete score on admission to the PACU. Adverse events occurrence is exposed in Table 4: hypertension, bradycardia, postoperative headache occurred rarely but more frequently in XR group; PONV was more common in XR group and only nausea was noticed; no patient experienced vomiting in the two groups. Hypotension occurred rarely but more frequently in SR group. No patient experienced awareness.

\section{Discussion}

In this study, we verify that xenon anesthesia is associated with better arterial oxygenation and cardiovascular stability in morbidly obese patients. As argued by Wood et al [19] the effect on $\mathrm{AaDO} 2$ of a high-density gas mixture may be due to a more uniform distribution of ventilation during anesthesia; however, xenon, which pharmacologically is a NMDA receptor antagonist, is not considered a biologically inert gas $[12-15,22,23]$ and the improvement of $\mathrm{PaO} 2 / \mathrm{FiO} 2$ ratio may be related not only to "high-density effect" of the inhaled mixture but also to its organoprotective and preconditioning effects [12-15]. Recovery times recorded after xenon anesthesia were faster according to the blood-gas coefficient of the molecule [16]; no considerable difference was noticed with respect to normal-weight patients trials, taking into account the sample size of our study [9]. Xenon anesthesia was characterized by a significative higher arterial systolic pressure and by a minimal variation from preoperative baseline (Tables 1 and 2). Heart rate was lower; more evident were bradycardia, hypertension, and incidence of postoperative nausea; airway pressure was significantly and constantly increased. All these data are aligned to normalweight patients trials findings and experimental literature about xenon anesthesia $[9,17,18,24]$.

An unexpected and significative reduction of opioid consumption in xenon group was found. Xenon exerts a potent analgesic action due to NMDA receptor inhibition [25] which may explain the lower overall remifentanil consumption during surgery; however, wash in and wash out of xenon are very fast $[9,13]$, and NMDA receptor blocking ability may not explain an effect on pain pathways up to 72 hours. Nowadays the evidence is that xenon is able to modulate long-term pathways $[12,14,22]$ which are considered the end effectors producing the long-term organoprotective effects of the gas. It is possible that a longterm modulation of pain could be inserted in such scenario but further studies are required.

\section{References}

[1] G. Hedenstierna, L. Tokics, A. Strandberg, et al., "Correlation of gas exchange impairment to development of atelectasis during anaesthesia and muscle paralysis," Acta Anaesthesiologica Scandinavica, vol. 30, no. 2, pp. 183-191, 1986.
[2] G. Hedenstierna, "Gas exchange during anaesthesia," British Journal of Anaesthesia, vol. 64, no. 4, pp. 507-514, 1990.

[3] P. Pelosi, M. Croci, I. Ravagnan, et al., "Respiratory system mechanics in sedated, paralyzed, morbidly obese patients," Journal of Applied Physiology, vol. 82, no. 3, pp. 811-818, 1997.

[4] P. Pelosi, M. Croci, I. Ravagnan, et al., "The effects of body mass on lung volumes, respiratory mechanics, and gas exchange during general anesthesia," Anesthesia and Analgesia, vol. 87, no. 3, pp. 654-660, 1998.

[5] H. U. Rothen, B. Sporre, G. Engberg, G. Wegenius, and G. Hedenstierna, "Airway closure, atelectasis and gas exchange during general anaesthesia," British Journal of Anaesthesia, vol. 81, no. 5, pp. 681-686, 1998.

[6] J. Sprung, D. G. Whalley, T. Falcone, D. O. Warner, R. D. Hubmayr, and J. Hammel, "The impact of morbid obesity, pneumoperitoneum, and posture on respiratory system mechanics and oxygenation during laparoscopy," Anesthesia and Analgesia, vol. 94, no. 5, pp. 1345-1350, 2002.

[7] G. I. Bardoczky, J.-C. Yernault, J.-J. Houben, and A. A. d'Hollander, "Large tidal volume ventilation does not improve oxygenation in morbidly obese patients during anesthesia," Anesthesia and Analgesia, vol. 81, no. 2, pp. 385-388, 1995.

[8] J. Sprung, D. G. Whalley, T. Falcone, W. Wilks, J. E. Navratil, and D. L. Bourke, "The effects of tidal volume and respiratory rate on oxygenation and respiratory mechanics during laparoscopy in morbidly obese patients," Anesthesia and Analgesia, vol. 97, no. 1, pp. 268-274, 2003.

[9] R. Rossaint, M. Reyle-Hahn, J. Schulte Am Esch, et al., "Multicenter randomized comparison of the efficacy and safety of xenon and isoflurane in patients undergoing elective surgery," Anesthesiology, vol. 98, no. 1, pp. 6-13, 2003.

[10] F. Wappler, R. Rossaint, J. Baumert, et al., "Multicenter randomized comparison of xenon and isoflurane on left ventricular function in patients undergoing elective surgery," Anesthesiology, vol. 106, no. 3, pp. 463-471, 2007.

[11] J.-H. Baumert, M. Hein, K. E. Hecker, S. Satlow, J. Schnoor, and R. Rossaint, "Autonomic cardiac control with xenon anaesthesia in patients at cardiovascular risk," British Journal of Anaesthesia, vol. 98, no. 6, pp. 722-727, 2007.

[12] D. Ma, T. Lim, J. Xu, et al., "Xenon preconditioning protects against renal ischemic-reperfusion injury via hif- $1 \alpha$ activation," Journal of the American Society of Nephrology, vol. 20, no. 4, pp. 713-720, 2009.

[13] R. D. Sanders and M. Maze, "Xenon: from stranger to guardian," Current Opinion in Anaesthesiology, vol. 18, no. 4, pp. 405-411, 2005.

[14] D. Cattano, S. Valleggi, D. Ma, et al., "Xenon induces transcription of ADNP in neonatal rat brain," Neuroscience Letters, vol. 440, no. 3, pp. 217-221, 2008.

[15] G. Natale, D. Cattano, A. Abramo, et al., "Morphological evidence that xenon neuroprotects against N-methyl-DLaspartic acid-induced damage in the rat arcuate nucleus: a time-dependent study," Annals of the New York Academy of Sciences, vol. 1074, pp. 650-658, 2006.

[16] T. Goto, K. Suwa, S. Uezono, F. Ichinose, M. Uchiyama, and S. Morita, "The blood-gas partition coefficient of xenon may be lower than generally accepted," British Journal of Anaesthesia, vol. 80, no. 2, pp. 255-256, 1998.

[17] E. Calzia, W. Stahl, T. Handschuh, et al., "Respiratory mechanics during xenon anesthesia in pigs: comparison with nitrous oxide," Anesthesiology, vol. 91, no. 5, pp. 1378-1386, 1999.

[18] H. Rueckoldt, B. Vangerow, G. Marx, et al., "Xenon inhalation increases airway pressure in ventilated patients," Acta Anaesthesiologica Scandinavica, vol. 43, no. 10, pp. 1060-1064, 1999. 
[19] L. D. H. Wood, A. C. Bryan, and S. K. Bau, "Effect of increased gas density on pulmonary gas exchange in man," Journal of Applied Physiology, vol. 41, no. 2, pp. 206-210, 1976.

[20] H. Zetterström, "Assessment of the efficiency of pulmonary oxygenation. The choice of oxygenation index," Acta Anaesthesiologica Scandinavica, vol. 32, no. 7, pp. 579-584, 1988.

[21] J. Aboab, B. Louis, B. Jonson, and L. Brochard, "Relation between $\mathrm{PaO} 2 / \mathrm{FIO} 2$ ratio and FIO2: a mathematical description," Intensive Care Medicine, vol. 32, no. 10, pp. 1494-1497, 2006.

[22] S. Valleggi, A. O. Cavazzana, R. Bernardi, et al., "Xenon upregulates several genes that are not up-regulated by nitrous oxide," Journal of Neurosurgical Anesthesiology, vol. 20, no. 4, pp. 226-232, 2008.

[23] J. H. Baumert, M. Hein, C. Gerets, T. Baltus, K. E. Hecker, and R. Rossaint, "The effect of xenon on isoflurane protection against experimental myocardial infarction," Journal of Cardiothoracic and Vascular Anesthesia, vol. 23, no. 5, pp. 614-618, 2009.

[24] M. Coburn, O. Kunitz, C. C. Apfel, M. Hein, M. Fries, and R. Rossaint, "Incidence of postoperative nausea and emetic episodes after xenon anaesthesia compared with propofolbased anaesthesia," British Journal of Anaesthesia, vol. 100, no. 6, pp. 787-791, 2008.

[25] T. Fukuda, C. Nishimoto, S. Hisano, M. Miyabe, and H. Toyooka, "The analgesic effect of xenon on the formalin test in rats: a comparison with nitrous oxide," Anesthesia and Analgesia, vol. 95, no. 5, pp. 1300-1304, 2002. 


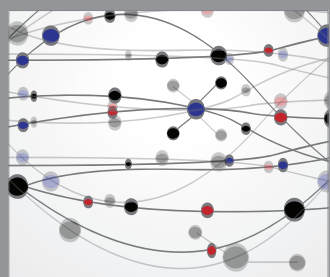

The Scientific World Journal
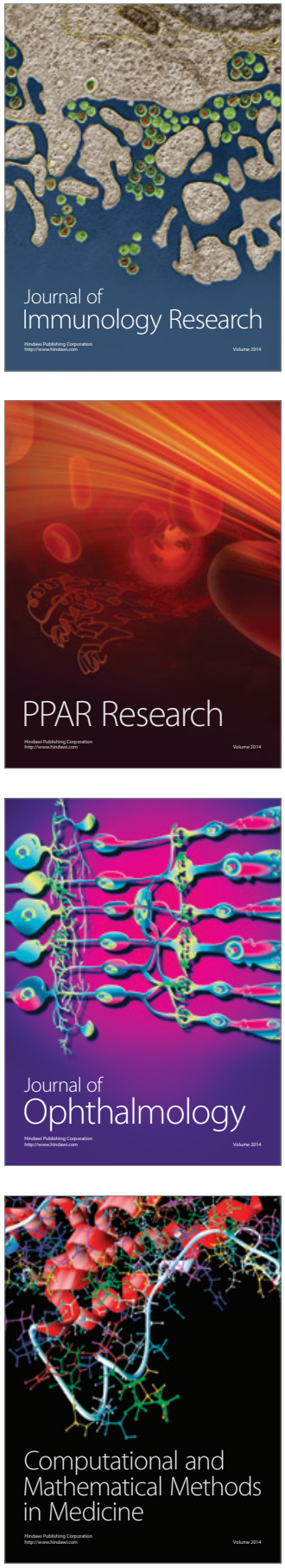

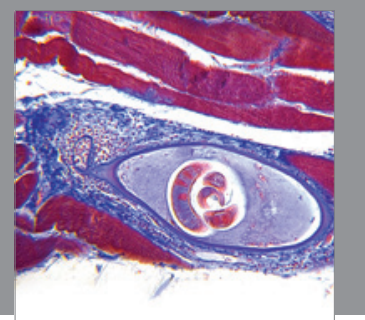

Gastroenterology

Research and Practice
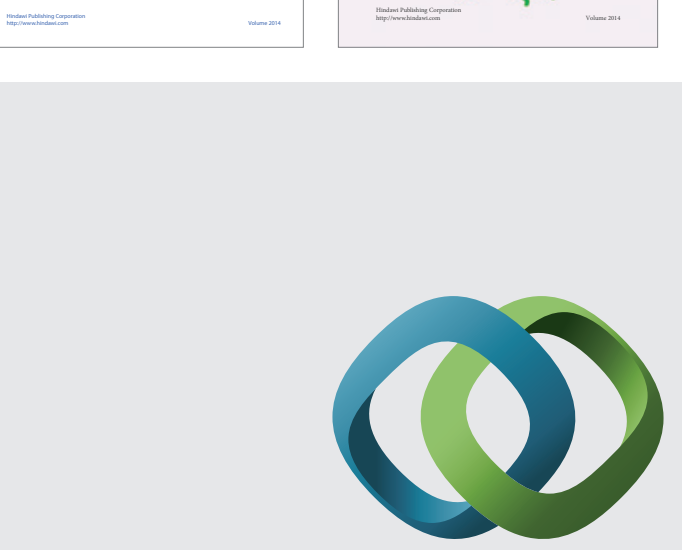

\section{Hindawi}

Submit your manuscripts at

http://www.hindawi.com
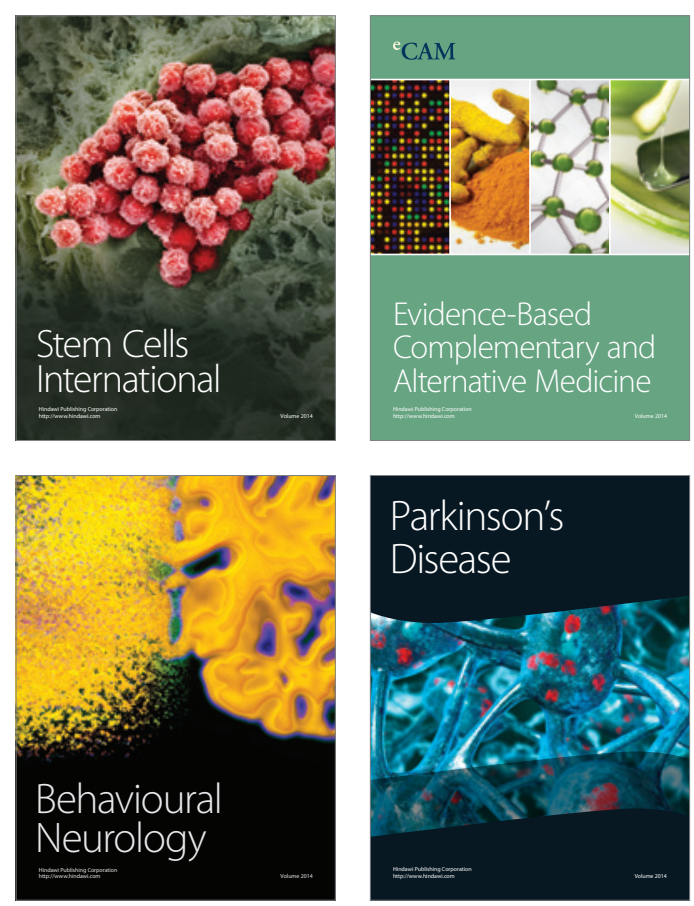

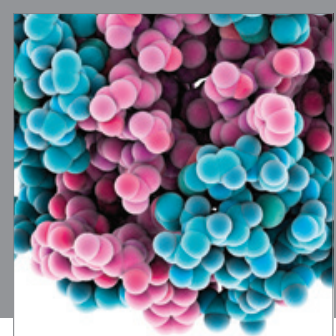

Journal of
Diabetes Research

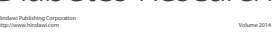

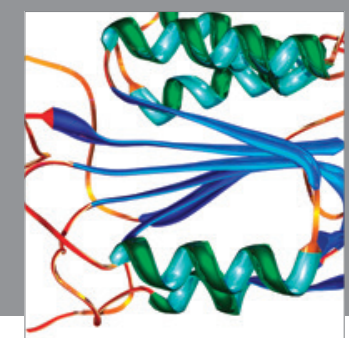

Disease Markers
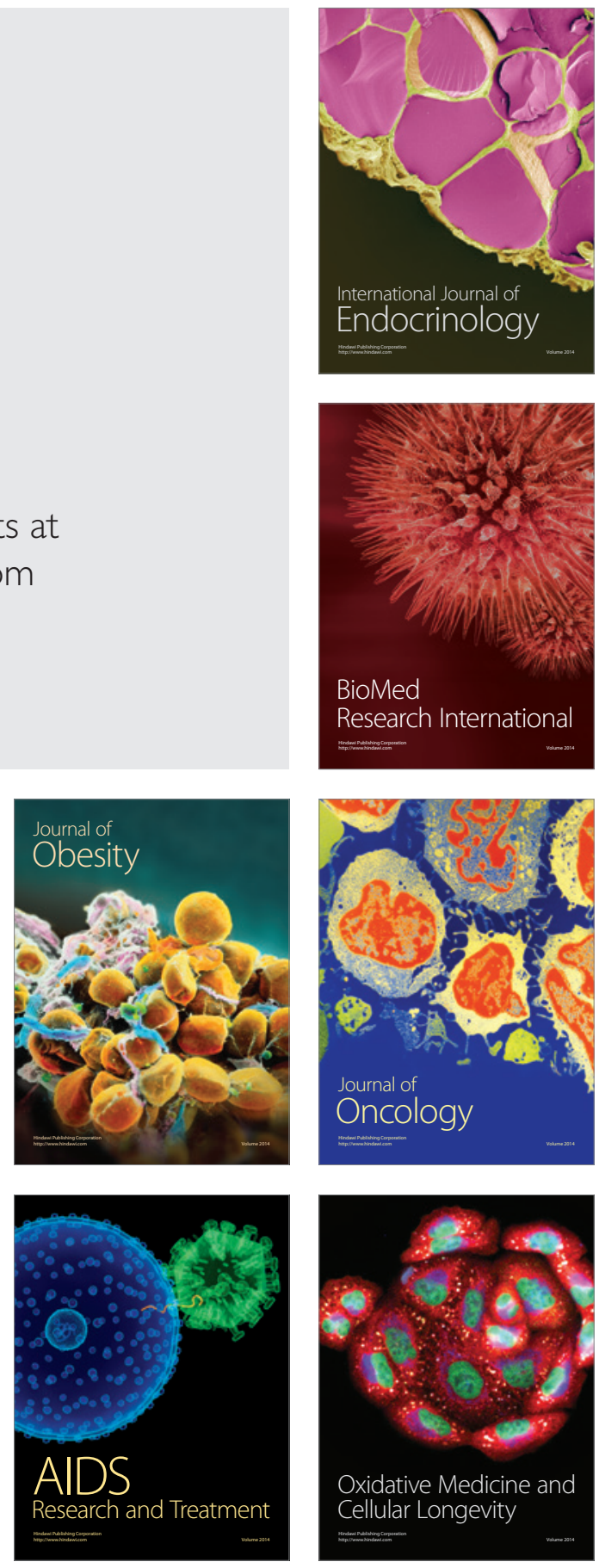